\section{Manejo quirúrgico de lesión quística periapical}

Surgical management of a periapical cyst injury. Case Report

\section{María Medina Mosqueira ${ }^{1}$}

${ }^{1}$ Estudiante de la especialidad de Endodoncia-
Carielogía, Facultad de Odontología de la
Universidad Nacional Mayor de San Marcos.

Correspondencia:

C.D. María Medina Mosqueira

Calle. Melitón Carbajal N. ${ }^{\circ}$ 153, Urb. San Juanito, San Juan de Miraflores. Lima - Perú

Teléf. 2833790

mmedinamos@hotmail.com radiográfico, y el tratamiento de conducto seguido por apiceptomía. El resultado clínico y radiológico a corto plazo fue favorable.

Palabras clave: Quiste radicular, Apiceptomía, Lesión apical crónica.

\begin{abstract}
Diagnosis and surgical management of dental root injuries suppose an extremely controversial question for dentist. Bearing in mind, that periapical cyst represents the most frequent injury in the maxilla, and that its differential diagnosis with chronic apical periodontitis shows a special complexity, decisions taken for its treatment acquires a major transcendence. the aim of this clinical case is to show clinical, radiographic Periapical Cyst diagnosis as long as its treatment by apicoectomy. Clinical and radiologic short-term outcome were favorable.
\end{abstract}

Key words: Root cyst, Apicoectomy, Chronic apical injury.

\section{Introducción}

\section{Concepto quiste periapical}

El término quiste es derivado de la voz griega Kystis, que significa saco o vesícula.

El quiste periapical es una lesión inflamatoria de los maxilares formada en el periápice de dientes con pulpa necrótica e infectada, siendo considerado una secuela directa de un granuloma apical. ${ }^{1}$

La transformación quística ocurre por estimulación de los restos epiteliales de Malassez presentes en el ligamento periodontal, en respuesta a un estímulo inflamatorio, a partir del momento en que bacterias y sus productos, que anteriormente ocupaban la pulpa dental, avanzan hacia el exterior del sistema de conductos radiculares hasta llegar a los tejidos periapicales, culminando con el establecimiento de una respuesta inmune. $^{2}$

Los mecanismos inmunológicos desencadenados se relacionan directamente con la patogénesis de los quistes periapicales y tanto la respuesta inmune celular, mediada principalmente por los linfocitos $T$, como la respuesta inmune humoral, caracterizada especialmente por la producción de anticuerpos, constituyen parte de ese proceso. ${ }^{1}$

Los quistes son lesiones frecuentes y clínicamente importantes porque algunos de ellos son agresivos y, por lo tanto, destructivos produciendo signos y síntomas relevantes, especialmente cuando se desarrollan y se infectan. ${ }^{1}$

\section{Histogénesis del quiste periapical}

Se inicia una respuesta inflamatoria en el periápice, incluso antes de que la pulpa esté totalmente necrótica. Dentro de los agentes patógenos causantes de la lesión, se encuentran endotoxinas bacterianas, sustancias mediadoras de la inflamación y tejido pulpar deteriorado, que pasan a través del foramen apical hacia el periápice, así como también irritantes mecánicos que hayan sido introducidos hacia el espacio del ligamento periodontal durante el procedimiento endodóntico, dando inicio a un proceso inflamatorio crónico mediado por el tejido vascular de esta zona que pueden evolucionar en granuloma periapical. ${ }^{3}$
Esta respuesta inflamatoria se considera que incrementa la producción del factor de crecimiento de queratinocitos (KFG) que estimulan la proliferación de restos epiteliales de Malassez (REM) localizados en el ligamento periodontal en las lesiones periapicales inflamatorias, iniciando así la formación de un quiste. ${ }^{4}$ Los restos epiteliales de $\mathrm{Ma}$ lassez son restos de la vaina epitelial de Hertwig en el ligamento periodontal que se encuentran en estado inactivo y no muestran actividad mitótica ${ }^{5}$. Sin embargo, cuando la inflamación involucra el ligamento periodontal, los restos son estimulados y empiezan a proliferar. ${ }^{2}$ Microscópicamente, casi todos los quistes periapicales están parcial o completamente recubiertos por epitelio escamoso estratificado no queratinizado. ${ }^{6}$ El epitelio puede tener hiperplasia, exocitosis, en la cual predominan los leucocitos polimorfonucleares. A veces, se encuentran células productoras de moco en el epitelio de los quistes periapicales. Además, se pueden observar células ciliadas, posiblemente como resultado de metaplasia en el epitelio, con células mucosecretoras. ${ }^{7}$

Los depósitos de colesterol se encuentran en la cápsula de tejido conjuntivo 
en el $30-40 \%$ de los quistes periapicales, donde pueden provocar reacción a cuerpo extraño.

Los cristales de colesterol dan al líquido quístico el típico color amarillo brillante. ${ }^{8}$

El epitelio, y a veces el tejido conjuntivo de un número no significativo de quistes odontogénicos, presenta acúmulos de estructuras laminares en forma de semiluna llamados Cuerpos hialinos (de Rushton). ${ }^{2}$

\section{Diagnóstico diferencial entre quiste radicular y periodontitis apical cró- nica}

Las pruebas que van a ayudarnos a efectuar el diagnóstico diferencial son la vitalometría pulpar, la radiología, ya sea convencional o avanzada. ${ }^{3}$

\section{Pruebas vitalométricas}

Las pruebas de vitalidad pulpar nos ofrecen la posibilidad, por un lado, de diferenciar los quistes radiculares de otras patologías periapicales no endodónticas, como cementomas, quistes globulomaxilares, donde la vitalidad de la pulpa está conservada; y, por otro lado, diferenciar qué dientes están afectados por la patología quística y cuáles no. ${ }^{1}$

\section{Pruebas térmicas}

Humford describe el uso de la gutapercha caliente para la realización de estas pruebas. Con respecto a las pruebas térmicas basadas en el frío, se han usado trocitos de hielo (Dachi), nieve carbónica (Obwegeser y Stein Hauser), cloruro de etilo y más modernamente diclordifluormetano. La principal desventaja de estas pruebas es que la temperatura a que sometemos el diente es difícilmente objetivable. ${ }^{3}$

\section{Radiología convencional}

Radiológicamente, no se puede establecer una diferenciación absoluta y objetiva entre un quiste radicular y un granuloma apical. Algunos autores como Grossman o Wood, se atreven a realizar un diagnóstico radiográfico aproximado, indicando que el quiste presenta unos límites más definidos e incluso se delimita con una zona más esclerosada $y$, por lo tanto, más radiopaca. ${ }^{8}$

Otros elementos de diferenciación serían la separación de los ápices radicu- lares, causada por la presión del líquido quístico o, incluso, la posibilidad de observar o palpar esa fluctuación. ${ }^{4}$ También se indica que a mayor tamaño, mayor probabilidad de que la lesión haya evolucionado, y por tanto, se haya transformado en quiste, al producirse la proliferación de los restos epiteliales de Malassez y la posterior lisis de parte de ellos. ${ }^{4}$

\section{Tratamiento}

Se pueden tratar los quistes periapicales:

1. Por vía endodóncica. Tratar los conductos radiculares, con o sin sobreobturación intencionada con pasta reabsorbibles. ${ }^{9}$

2. Mediante procedimiento quirúrgico. Es decir, la exéresis del quiste. Se debe efectuar drenaje, ya sea abriendo el propio diente o a través del tejido blando mandibular circundante si se ha desarrollado celulitis. Se requieren, asimismo, antibióticos dirigidos contra los microorganismos agresores. ${ }^{10}$

3. Exodoncia. Extracción del diente que ha sido afectado por el quiste. Esta técnica solo se realiza en aquellos casos donde hay una afectación grave, ya que el objetivo es eliminar el quiste manteniendo las estructuras dentarias. ${ }^{2}$

\section{Presentación de caso clínico}

Paciente de sexo femenino de 20 años de edad que llega a la consulta porque "va a realizarse curaciones y además hace tiempo le salió un bulto en el paladar y quiere saber qué es" (Fig. 1); el paciente refiere no tener ninguna enfermedad ni alergias. ABESG; LOTEP.

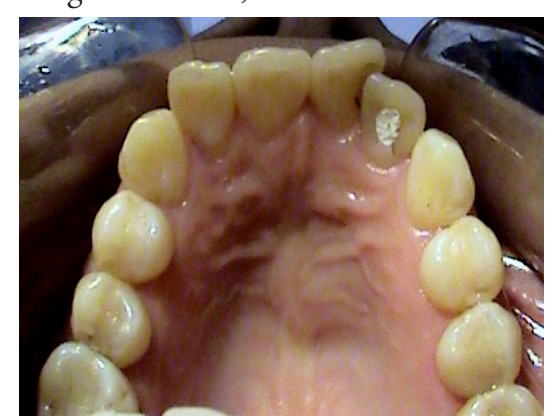

Fig 1. Pieza dentaria 12 (Incisivo Lateral Superior Derecho)

En la radiografía periapical, se observa una zona radiolúcida en el área apical del incisivo lateral derecho, el cual presenta caries recidivante en distal, se aprecia una imagen radiolúcida circunscrita y con un halo radiopaco alrededor de ella, características del quiste periapical. La paciente no presenta sintomatología. (Fig. 2)

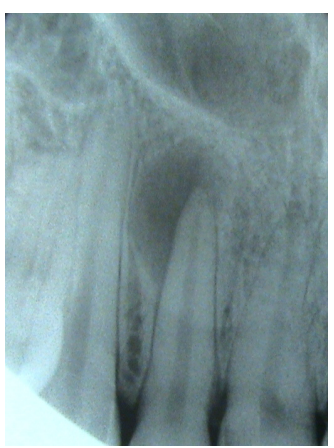

Fig 2. Pieza dentaria 12 con IRL en el ápice.

\section{Plan de tratamiento}

El tratamiento indicado es la endodoncia de la pieza así como la apicectomía del diente afectado. (Fig. 3)

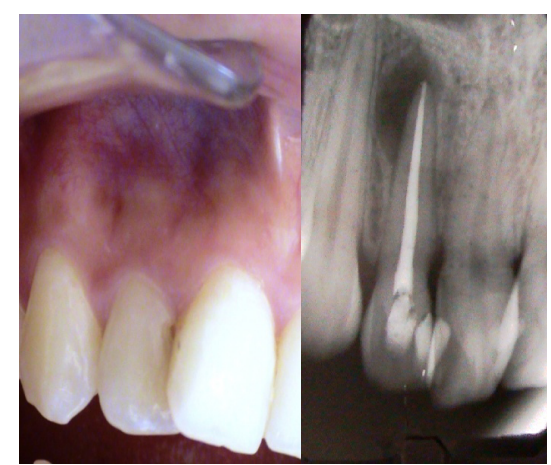

Fig 3. Pieza 12 con tratamiento de conducto.

\section{Apiceptomía}

Se procedió a infiltrar el anestésico local xilocaína en los centrales superiores izquierdo y derecho, lateral y canino derechos así como refuerzo por palatino. Se realizó una incisión Newman para colgajo mucoperióstico abarcando central, lateral y canino derechos (Fig 4). Con legra, se dejó expuesta la tabla ósea vestibular del maxilar, se hizo la osteotomía con fresa quirúrgica y pieza de mano de alta velocidad a nivel del ápice del diente afectado, llevándola del centro a la periferia. Utilizando cureta de alveolo, se procedió a la enucleación total de la lesión. Después, se realizó el corte del extremo apical del diente afectado y el bruñido de la gutapercha, lavándose después la cavidad expuesta con suero fisiológico; por último, se procedió a suturar. 


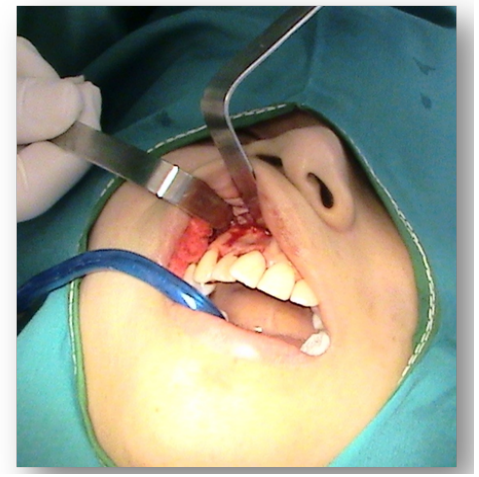

Fig 4. Paciente en el proceso de la apiceptomía.

Se dio instrucción médica de antimicrobiano y analgésico antiinflamatorio, así como las recomendaciones pertinentes, aplicación de Hielo por 20 min con intermedios de $5 \mathrm{~min}$. Dieta blanda.

Una semana después, se procedió al retiro de los puntos de sutura. La paciente cursó asintomática, con ligera inflamación dos días posteriores a la intervención, exenta de proceso infeccioso en el área operada. Los resultados, a los 3 y 6 meses, se observan en las figuras 5 y 6 .

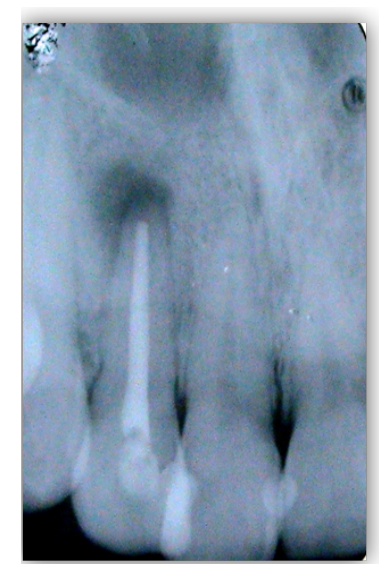

Fig 5. Evaluación radiográfica a los 3 meses post cirugía. Se observa una disminución de la IRL en el ápice.

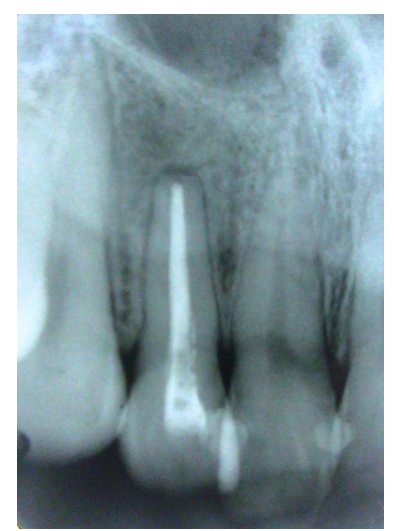

Fig 6. Evaluación radiográfica a los 6 meses post cirugía. No se observa ninguna IRL en el ápice.

\section{Discusión}

Una de las principales razones del fracaso de un tratamiento endodóntico es la persistencia de la lesión quística a nivel apical. Desafortunadamente, por medios clínicos o radiográficos, no se puede determinar si la lesión es granulomatosa o si es quística, menos aún si esta lesión es verdadera o en forma de bolsa quística, y la única forma de saberlo es por medios histológicos; pero para tal efecto, sería necesaria la remoción quirúrgica de la lesión. ${ }^{11}$ Una pregunta que frecuentemente se hacen los clínicos, es si una lesión quística puede ser tratada mediante un tratamiento endodóntico no quirúrgico o quirúrgico. ${ }^{9}$ No hay una evidencia concluyente que permita contestar esta pregunta. Sin embargo, no toda lesión quística sana por medios endodónticos convencionales, y algunas lesiones requieren tratamiento quirúrgico debido a factores que influyen en la reparación. ${ }^{9}$

Las lesiones con menor oportunidad de sanar son los quistes verdaderos porque la lesión no depende solamente de la presencia o ausencia de irritantes en el canal radicular. Los quistes verdaderos, particularmente los más grandes, son lesiones autosostenidas. ${ }^{9}$

Por otro lado, en la defensa por la alternativa quirúrgica, no cerramos la puerta a un posible éxito con una endodoncia perfecta, pero defendemos además el valor diagnóstico de la cirugía periapical.

\section{Conclusiones}

En las lesiones de gran tamaño (más de $10 \mathrm{~mm}$ de diámetro) se propugna, además del tratamiento endodóntico, un abordaje quirúrgico con fines tanto diagnósticos como terapéuticos.

En este caso en particular, se optó por la alternativa quirúrgica; y la paciente fue evaluada por 10 meses post cirugía apical, obteniendo resultados favorables.

\section{Referencias bibliográficas}

1. Álvarez Patricia, Fernandes Rivadávio, Gordón Antonio, Batistade Élia, Andrade Rejane. Mecanismos inmunológicos involucrados en la Patogenia de los quiste periapicales. Rev ADM 2004; LXI(2): 54-58.

2. Leyva HER, Tapia VJL, Quezada RD, Ortiz RE. Factores involucrados en el desarrollo y expansión del quiste periapical. Rev Odont Mex 2006; 10(1): 36-41.

3. Gallego D, Torres D, García M, Romero MM, Infante P, Gutiérrez JL. Diagnóstico diferencial y enfoque terapéutico de los quistes radiculares en la práctica odontológica cotidiana. Medicina Oral 2002; 7 : 54-62.

4. Aggarwal V, Logani A, Shah N. The Evaluation of computed tomography scans and ultrasounds in the differential diagnosis of periapical lesions. J Endod. 2008 Nov; 34(11): 1312.

5. VALOIS Carolina, COSTA Junior. Periapical Cyst Repair After Nonsurgical Endodontic Therapy - Braz Dent J (2005) 16(3): 254-258.

6. Rodríguez Luis,Guiardinu Reina, Arte Manuela y Blanco Antonio. Quistes de los maxilares. Rev Cubana Estomatol 2006; 43(4).

7. Kumasawa M. Effect of traumatic occlusion on periapical lesions in rats. J Endod. 1995, 21(7): 37276.

8. Grossman L. Terapéutica de los conductos radicualres. 4ta. edición. Buenos Aires. 1959: 95-115.

9. Simon J. Incidence of periapical cysts inrelation to the root canal. J Endod. 1980, 6: 845-8.

10. Laskin DM. Cysts of the jaw and oral and facial soft tissues. Oral and maxillofacial Surgery. Vol II. 1985: 427-87.

11. Takiguchi M, Fujiwara T, Sobue $S$, Ooshima T. Radicular cyst associated with a primary molar following pulp therapy: a case report. Int J Paediatr Dent 2001; 11:452-5.

Fecha de recepción: 12-04-10

Fecha de aprobación: 10-06-10 